\section{Comment}

Poverty, maternal psychiatric illness, and family violence were all strongly associated with higher rates of probable psychiatric disorders among Brazilian 7-14 year olds. Though it is tempting to conclude that the social adversities caused the children's behavioural problems, the children's problems may have evoked maternal depression or harsh discipline. Another possibility is that the social adversities and behavioural problems both arose from unmeasured factors. The higher rate of behavioural problems in the favela could be accounted for by the associated poverty, maternal psychiatric illness, and domestic violence; future studies should investigate the possible role of social capital and social networks in buffering the impact of these social adversities. It did not need this study to identify the importance of tackling poverty, parental mental illness, or family violence in the developing world, but tackling these problems is likely to have the additional benefit of improving child mental health. Moreover, our findings help to identify marginalised groups of "at risk" children and families who should be targeted for preventive or curative services.

Contributors: Both authors devised the study and the data collection instruments and analysed the data. RG obtained the funding. BF oversaw data collection. RG is guarantor of the study.

Funding: Wellcome Trust.

Competing interests: None declared.

1 Hackett R, Hackett L. Child psychiatry across cultures. Int Rev Psychiatry 1999;11:225-35.

Goodman R, Ford T, Simmons H, Gatward R, Meltzer H. Using the strengths and difficulties questionnaire (SDQ) to screen for child psychiatric disorders in a community sample. Br J Psychiatry 2000;177:534-9.

3 Goodman R, Renfrew D, Mullick M. Predicting type of psychiatric disorder from strengths and difficulties questionnaire (SDO) scores in child

4 Goodman R, Ford T, Richards H, Gatward R, Meltzer H. The development and well-being assessment: description and initial validation of an integrated assessment of child and adolescent psychopathology. J Child Psychol Psychiatry 2000;41:645-55.

5 Mari J, Williams P. A comparison of the validity of two psychiatric screening questionnaires (GHQ-12 and SRQ-20) in Brazil, using relative operating characteristic (ROC) analysis. Psychol Med 1985;15:651-9.

(Accepted 13 June 2001)

\title{
Skin cancer surveillance in renal transplant recipients: questionnaire survey of current UK practice
}

\author{
P N Harden, S M Reece, A A Fryer, A G Smith, H M Ramsay
}

Department of Nephrology, North Staffordshire Hospital, Stoke on Trent ST4 7LN

P N Harden nephrologist

S M Reece research nurse

Department of Biochemistry, North Staffordshire Hospital

A A Fryer biochemist

Department of Dermatology, North Staffordshire

Hospital

A G Smith

dermatologist

H M Ramsay dermatologist

Correspondence to: P N Harden pnharden@ netscape.net

BMJ 2001;323:600-1

\section{bmj.com}

The questionnaire is available on the BMJ's website
The risk of non-melanoma skin cancer is increased after organ transplantation, with a prevalence and annual incidence for the United Kingdom reported at $16.5 \%$ and $7.1-10.6 \%$ respectively. ${ }^{12}$ Non-melanoma skin cancer presents at an earlier age and spreads more rapidly in people who have received a transplant than in the general population, and it often occurs at more than one site. These factors result in substantial morbidity and a sevenfold increase in mortality from the disease, although absolute death rates are low. ${ }^{3}$ The high incidence, rapid growth, and increased metastatic potential of non-melanoma skin cancer in transplant recipients justifies a surveillance programme. ${ }^{13}$ We did a survey to establish current practice in skin cancer surveillance in UK centres managing renal transplant recipients.

\section{Methods and results}

We sent a questionnaire to 65 UK centres that follow up renal transplant recipients. The questionnaire asked whether they did skin cancer surveillance, which staff did the surveillance, and what the policy was for educating patients about the risk of skin cancer.

Sixty one centres (26 surgical and 35 nephrology centres) responded, collectively managing 16264 renal transplant recipients. Among the 61 respondents, 31 were consultant nephrologists or transplant surgeons and 24 were specialist renal transplant nurses. The table shows the results of the questionnaire. On-site dermatology facilities were available in 54 centres. Thirteen centres did annual surveillance for skin cancer-by a dermatologist (2 centres), nurse practitioner (4), nephrologist or transplant surgeon (4), and a combination of nurse and nephrologist (3). Annual full skin examination (patient undressed to their underwear) was done in 12 of these 13 centres. Patients were educated about skin cancer before transplantation in 36 centres and after transplantation in 51. The mean number of transplant recipients followed up was significantly higher in surgical centres than in nephrology centres $(\mathrm{P}<0.0001)$ (table). Furthermore, a higher proportion of surgical centres provided education for patients (table). We

Skin cancer surveillance and education of transplant recipients followed up in 61 surgical and nephrology centres. Values are numbers (percentages) of centres unless stated otherwise

\begin{tabular}{lcc} 
& $\begin{array}{c}\text { Surgical centres } \\
(\mathbf{n}=\mathbf{2 6})\end{array}$ & $\begin{array}{c}\text { Nephrology } \\
\text { centres }(\mathbf{n}=35)\end{array}$ \\
\hline Mean (SD) No of recipients & $475(208)^{\star}$ & $113(67)$ \\
\hline Mean (SD) No of transplants per year & $64(32)$ & Not applicable \\
\hline Percentage of white patients & $84.2 \dagger$ & 90.2 \\
\hline $\begin{array}{l}\text { Transplant clinic taking place } \\
\text { concurrently }\end{array}$ & $25(96)$ & $20(57)$ \\
\hline On-site dermatology services & $22(85)$ & $32(91)$ \\
\hline Education of patients about skin cancer: & & \\
\hline Before transplantation & $19(73) \S$ & $17(49)$ \\
\hline After transplantation & $24(92)$ l & $27(77)$ \\
\hline Skin cancer surveillance (annual): & $5(19)$ & $8(23)$ \\
\hline Full body examination & $4(80)$ & $8(100)$ \\
\hline Screening performed by: & $1(20)$ & $1(13)$ \\
\hline Dermatologist & $1(20)$ & $3(38)$ \\
\hline$\quad$ Nephrologist or surgeon & $1(20)$ & $3(38)$ \\
\hline$\quad$ Nurse & $2(40)$ & $1(13)$ \\
\hline$\quad$ Nephrologist or nurse & $2(40)$ & $2(25)$ \\
\hline Training provided
\end{tabular}

${ }^{*} \mathrm{P}<0.0001$ (two sided $t$ test); $\mathrm{P}=0.057$ (Fisher's exact test, $1 \mathrm{df}$ ); $\S \mathrm{P}=0.051$ (Fisher's exact test, $1 \mathrm{df}$ ); $\mathbb{I P}=0.018$ (Fisher's exact test, $1 \mathrm{df}$ ). All $\mathrm{P}$ values are uncorrected for multiple comparisons. 
found no difference in the proportion of surgical or nephrology centres that provided skin cancer surveillance, full skin examination, or specific training for clinicians performing surveillance (table), regardless of the size of the unit (data not shown).

\section{Comment}

Skin cancer surveillance is available only to a minority of UK renal transplant recipients. We found no difference between surveillance strategies in surgical and nephrology centres.

Surveillance of individuals with atypical mole syndrome in the general population is well established. Such people have an estimated cumulative 10 year risk of melanoma of $11 \%$, compared with a $32 \%$ prevalence of non-melanoma skin cancer in transplant recipients. ${ }^{1}$ Guidelines for annual screening of renal transplant recipients for non-melanoma skin cancer were recently established in the United States. ${ }^{3}$ We previously showed the benefit of nurse led surveillance in the United Kingdom, which facilitates earlier diagnosis and treatment of non-melanoma skin cancer, with a potential reduction in morbidity and mortality. ${ }^{2}$ Clinicians doing surveillance must have adequate training to maintain clinical competence; current levels of training are inadequate. Non-melanoma skin cancer often occurs on covered body sites ( $20 \%$ of cases ${ }^{1}$ ); such lesions could be missed in centres doing only limited skin examination.

Although advice and literature on avoidance of ultraviolet light are given at the time of transplantation, only a minority of patients remain aware of the risks and adopt adequate sun protection measures long term. ${ }^{5}$ Education of patients should start as soon as transplantation is recognised as a potential treatment and should continue long term.
All transplant recipients should have skin cancer surveillance, and all clinicians (general practitioners, specialist physicians and surgeons, and nurses) caring for transplant recipients should be aware of the risks. The higher prevalence of non-melanoma skin cancer in renal transplant recipients compared with the general population is largely due to long term immunosuppression. The prevalence of skin cancer is therefore also likely to be increased in patients taking immunosuppression for a range of non-renal clinical conditions.

We thank all of the nephrologists, transplant surgeons, specialist nurses, and transplant coordinators throughout the United Kingdom who completed and returned the questionnaires.

Contributors: PNH conceived and designed the study, wrote the draft manuscript, and is the guarantor for the paper. SMR distributed the questionnaires and liaised with individual units. AAF did the statistical analyses and collated the database. AGS advised on dermatological aspects of the study. HMR helped to design the study. AAF, AGS, and HMR reviewed the draft and final versions of the manuscript

Funding: Lord Trafford award from the Royal College of Nursing.

Competing interests: None declared.

1 Ramsay HM, Fryer AA, Reece S, Smith AG, Harden PN. Clinical risk factors associated with nonmelanoma skin cancer in renal transplant recipients. Am J Kid Dis 2000;36:167-76.

2 Harden PN, Fryer AA, Reece S, Smith AG, Ramsay HM. Annual incidence and predicted risk of nonmelanoma skin cancer in renal transplant recipients. Transplant Proceedings 2001;33:1302-4.

3 Kasiske BL, Vazquez MA, Harmon WE, Brown RS, Danovitch GM, Gaston RS, et al. Recommendations for the outpatient surveillance of renal transplant recipients. J Am Soc Nephrol 2000;11:S1-86.

4 Salopeck TG, Rigel DS, Kopf AW, Bart RS. Atypical mole syndrome: risk factor for cutaneous malignant melanoma and implications for management. J Am Acad Dermatol 1995;32:479-94.

5 Seukeran DC, Newstead CG, Cunliffe WJ. The compliance of renal transplant recipients with advice about sun protection measures. Br J Dermatol 1997;138:301-3.

(Accepted 18June 2001)

\title{
Seasonal variations in hospital admission for deep vein thrombosis and pulmonary embolism: analysis of discharge data
}

\author{
Fabrice Boulay, Frédéric Berthier, Grégory Schoukroun, Charles Raybaut, Yves Gendreike, \\ Bruno Blaive
}

Seasonal variation in fatal pulmonary embolism has been well documented by at least 23 reports comprising nearly 11000 cases. $^{1}$ Evidence is lacking, however, for seasonal variation in deep vein thrombosis-the only large hospital series available did not establish significant variation. ${ }^{2}$ We analysed hospital admissions for deep vein thrombosis and pulmonary embolism in France over four years.

\section{Methods and results}

We reviewed all cases with a discharge diagnosis of deep vein thrombosis or pulmonary embolism entered on the national hospital discharge register between 1995 and 1998. We used the international classification of diseases, ninth and 10th revisions (deep vein thrombosis: ICD-9 codes 451.1 and 451.2 and ICD-10 codes
I80.1 and I80.2; pulmonary embolism: ICD-9 code 415.1 and ICD-10 codes I26.0 and I26.9). This dataset is a collection of all discharges from public and non-profit making, short stay, or acute hospitals in France $(71 \%$ of hospital capacity). We included discharge data if the usual confirmatory tests-or specific fibrinolytic or surgical therapy-were mentioned. Usual confirmatory tests were venography or Doppler ultrasonography for deep vein thrombosis and a ventilation and perfusion lung scan, helicoidal computed tomography, or pulmonary angiography for pulmonary embolism.

The figure shows monthly data on admissions to hospital for deep vein thrombosis $(n=65081$, median age 69 years, $58 \%$ women, $95 \%$ medical patients) and pulmonary embolism $(\mathrm{n}=62237$, median age 68 years, $57 \%$ women, $96 \%$ medical patients), presented as 